\section{Cold polypectomy for nonampullary duodenal adenoma}

Cold polypectomy for colorectal polyps has been widely performed in Western countries and is now becoming widespread in Japan. Both cold forceps polypectomy (CFP) and cold snare polypectomy (CSP) are safe and efficient for colorectal polyps $[1,2]$. These procedures are excellent in regard to safety, in particular because electrocautery is not needed; thus, perforation or delayed bleeding rarely occurs $[1,2]$. However, there have been no reports of cold polypectomy for duodenal polyps.

A 70-year-old woman had a type Ila nonampullary duodenal lesion (4-mm diameter) in the second portion of the duodenum ( Fig. 1 a). CFP planned with two bites of a jumbo forceps (Radial Jaw 4 Jumbo Biopsy Forceps; Boston Scientific,
Natick, Massachusetts, USA) was used to resect the lesion ( Fig. 1 b). The pathological diagnosis was low grade adenoma. A 57-year-old man had a type Is nonampullary duodenal polyp (4-mm diameter) in the third portion of the duodenum. CSP with an oval snare (Profile Polypectomy Snare, $11 \mathrm{~mm}$; Boston Scientific) was used to resect the lesion endoscopically en bloc without submucosal injection or electrocautery ( $\bullet$ Fig.2a, $\bullet$ Fig. 2 b). The final pathological diagnosis was also low grade adenoma.

In both cases, the lesions were diagnosed as low grade adenoma before resection by magnifying endoscopy with narrowband imaging [3]. The ulcers were closed after resection with endoscopic clips, and neither patient had a complication, such as perforation or delayed bleeding. Both underwent upper gastrointestinal endoscopy 3 months after resection, which confirmed the morphological and pathological absence of residual tumor via biopsy findings ( $\bullet$ Fig. 1 c, $\bullet$ Fig. $2 c$ ).

To the best of our knowledge, this is the first report of cold polypectomy for duodenal lesions. Nonampullary duodenal adenomas/carcinomas are usually resected by endoscopic mucosal resection (EMR) or endoscopic submucosal dissection (ESD). However, when either EMR or ESD is performed for duodenal tumors, the risk for complications, such as perforation and delayed bleeding, is higher than when the procedure is performed for lesions in other parts of the digestive tract $[4,5]$. Cold polypectomy is exceptionally safe and may be effective treatment for nonampullary duodenal adenomas, especially smaller lesions.

\section{Endoscopy_UCTN_Code_TTT_1AR_2AF}

\section{Competing interests: None}
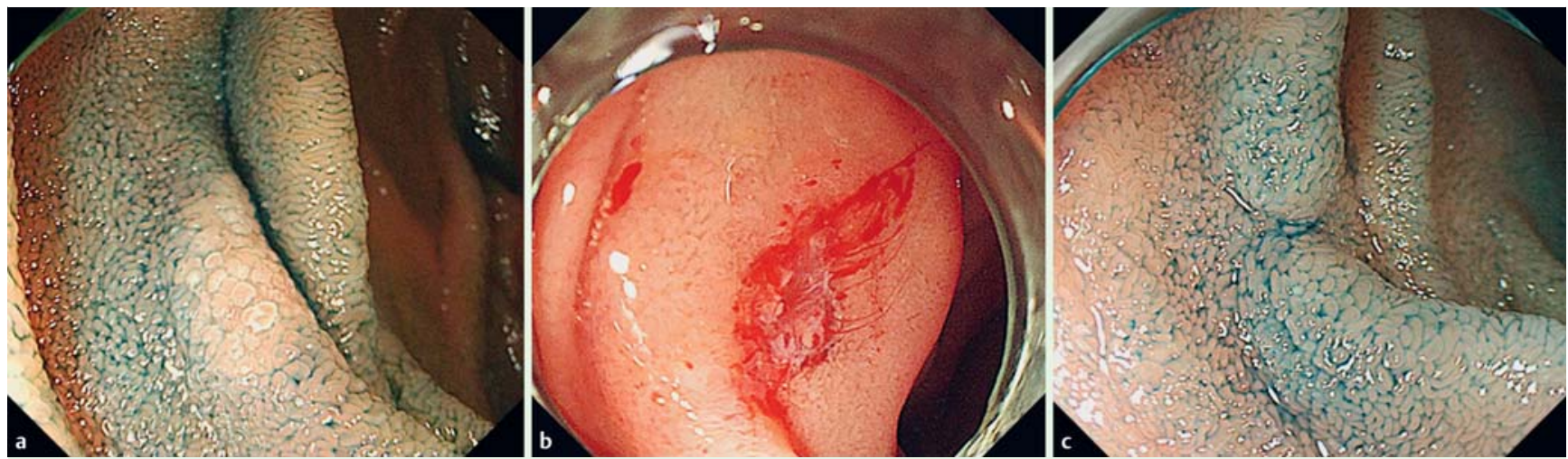

Fig. 1 Cold forceps polypectomy (CFP) for nonampullary duodenal adenoma. a Type lla nonampullary duodenal polyp (4-mm diameter) in the second portion of the duodenum in a 70-year-old woman. CFP planned with two bites of a jumbo forceps was used to resect the lesion. $\mathbf{b}$ Following resection, the mucosa around the ulcer was easily assessed by submucosal infusion with a water jet to identify morphologically residual tumor. $\mathbf{c}$ No residual tumor was found in or around the scar 3 months after CFP.
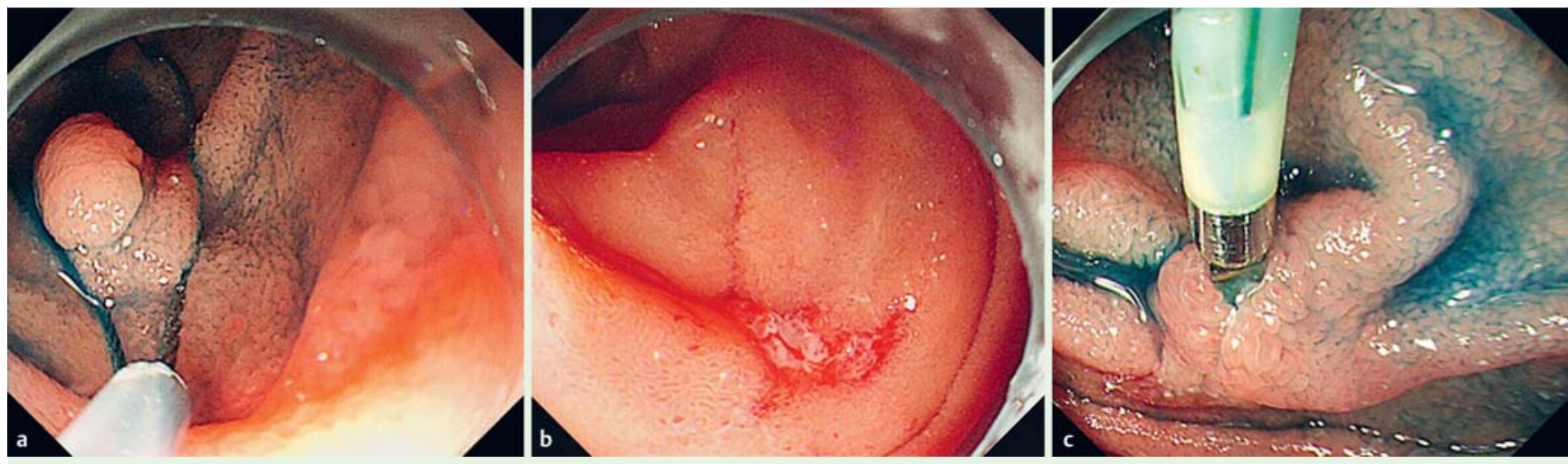

Fig. 2 Cold snare polypectomy (CSP) for type Is nonampullary duodenal polyp (4-mm diameter) in the third portion of the duodenum in a 57-year-old man. a The lesion was resected en bloc by CSP with an oval snare. b Following resection, the ulcer and surrounding mucosa were assessed with the application of water jet to the area. $\mathbf{c}$ No residual tumor was found 3 months after CSP, although there was mild inflammation caused by a retained endoscopic clip. 


\section{Daisuke Maruoka ${ }^{1,2}$, Makoto Arai ${ }^{1}$, Hideaki Ishigami ${ }^{1}$, Kenichiro Okimoto ${ }^{1}$, Tomoaki Matsumura ${ }^{1}$, Tomoo Naka- gawa', Osamu Yokosuka'}

${ }^{1}$ Department of Gastroenterology and Nephrology, Graduate School of Medicine, Chiba University, Chiba, Japan

${ }^{2}$ Clinical Research Center, Chiba University Hospital, Chiba, Japan

\section{References}

1 Repici A, Hassan C, Vitetta E et al. Safety of cold polypectomy for $<10 \mathrm{~mm}$ polyps at colonoscopy: a prospective multicenter study. Endoscopy 2012; 44: $27-31$

2 Ichise Y, Horiuchi A, Nakayama Y et al. Prospective randomized comparison of cold snare polypectomy and conventional polypectomy for small colorectal polyps. Digestion 2011; 84: 78-81

3 Maruoka D, Arai M, Matsumura T et al. Efficacy of magnifying endoscopy with narrow band imaging in the differential diagnosis of sporadic nonampullary duodenal adenoma and adenocarcinoma. Endoscopy 2012; 44 (Suppl. 01): A361

4 Ono $\mathrm{H}$, Nonaka S, Uedo $\mathrm{N}$ et al. Clinical issues of duodenal EMR/ESD [in Japanese with English abstract]. Stomach and Intestine (Tokyo) 2011; 46: 1669-1677

5 Maruoka D, Arai M, Kishimoto T et al. Clinical outcomes of endoscopic resection for nonampullary duodenal high-grade dysplasia and intramucosal carcinoma. Endoscopy 2013; 45: 138-141
Bibliography

Dol http://dx.doi.org/

10.1055/s-0034-1392668

Endoscopy 2015; 47: E477-E478

(C) Georg Thieme Verlag KG

Stuttgart · New York

ISSN 0013-726X

\section{Corresponding author}

\section{Makoto Arai, MD, PhD}

Department of Gastroenterology and Nephrology Graduate School of Medicine

Chiba University

Inohana 1-8-1

Chuo-Ku

Chiba City 260-8670

Japan

Fax: +81-43-226-2088

araim-cib@umin.ac.jp 